\title{
Birey-Ötesi Benlik Kurgusu Ölçeği Türkçe Formunun Psikometrik Özellikleri
}

\author{
Arş. Gör. Beyza KIRCA \\ İstanbul Sabahattin Zaim Üniversitesi, Eğitim Fakültesi, Eğitim Bilimleri Bölümü, \\ Rehberlik ve Psikolojik Danışmanlık Anabilim Dalı, İstanbul / Türkiye, \\ byzkrc79@gmail.com, ORCID: 0000-0002-3709-5846
}

\section{Prof. Dr. Halil EKŞİ}

Marmara Üniversitesi, Atatürk Eğitim Fakültesi, Eğitim Bilimleri Bölümü, Rehberlik ve Psikolojik Danışmanlık Anabilim Dalı, İstanbul / Türkiye, halileksi@marmara.edu.tr, ORCID: 0000-0001-7520-4559

\section{$\ddot{O} z$}

Bu çalışmada “Birey-Ötesi Benlik Ölçeği”nin Türkçe’ye uyarlanması ve psikometrik özelliklerinin incelenmesi amaçlanmıştır. Araştırmanın ilk çalışma grubu dilsel eşdeğerlik analizlerinin gerçekleştirildiği bir vakıf üniversitenin 30 lisans öğrencisinden; ikinci çalışma grubu geçerlik ve güvenirlik analizlerinin gerçekleştirildiği 376 ön lisans ve lisans öğrencisinden, üçüncü çalışma grubu ise ölçüt bağıntılı geçerlik çalışmaları için bir vakıf üniversitenin 108 lisans öğrencisinden oluşmaktadır. Çalışma kapsamında dilsel eşdeğerlik çalışmaları gerçekleştirilerek dilsel eşdeğerliğin sağlandığı görülmüştür. Sonrasında doğrulayıcı faktör analizi yapılmış ve madde faktör yükleri incelenmiş bir maddenin Türkçe formdan çıkarılması uygun görülmüştür. Ç1karma işleminden sonra tekrar doğrulayıcı faktör analizi ve gerekli modifikasyon gerçekleştirilmiş, 9 maddelik tek boyutlu yapının iyi uyum gösterdiği görülmüştür. Madde faktör yükleri .30 ile .67 arasında değişmektedir. Cronbach Alfa katsayısı .72 olarak tespit edilmiştir. Düzeltilmiş madde-toplam puan korelasyonları .28 ile .54 arasında değişmektedir. Spearman Brown iki yarı test değeri .72 olarak hesaplanmıştır. Yapılan incelemeler sonucunda "Birey-Ötesi Benlik Ölçeği”" Türkçe formunun dilsel 
eşdeğerliğe sahip, geçerli ve güvenilir bir ölçme aracı olduğu görülmüştür.

Anahtar Kelimeler: Benlik kurgusu; Birey-ötesi; Benötesi; Dilsel eşdeğerlik; Geçerlik; Güvenirlik; Doğrulayıcı faktör analizi.

\title{
The Psychometric Properties of the Turkish Form of The Metapersonal Self-Construal Scale
}

\begin{abstract}
The aim of this study is to adapt the Metapersonal Self Scale into Turkish and to examine its psychometric properties. The first sample was for the linguistic equivalence analysis and consisted of 30 undergraduate students from a private university; the second sample was for the validity and reliability analyses and consisted of 376 undergraduate students and the third sample was for the concurrent validity and consisted of 108 undergraduate students from a private university. The linguistic equivalence analyses were conducted and results showed that the linguistic equivalence was achieved. Confirmatory factor analysis was conducted and item factor loadings were examined, and an item was removed from the Turkish form. Confirmatory factor analysis and the suggested modification were performed after the removal. The 9-item one-dimensional structure was found to be fitting well. Item factor loadings range from .30 to .67. Cronbach's alpha coefficient was found to be .72. Corrected item-total score correlations range from .28 to .54 . Spearman Brown's split half test value was found to be .72 . These results show that the Turkish version of the Metapersonal Self Scale is a valid and reliable instrument with linguistic equivalence.
\end{abstract}

Keywords: Self construal; Metapersonal, Transpersonal, Linguistic equivalence, Reliability, Validity, Confirmatory factor analysis.

\section{Extended Summary}

\section{Purpose}

Self is basically a sense of continuity that a person experiences. In addition, self is the source of mental processes and has a filter function that filters perceptions (James, 1890/1981). Many concepts have been presented to understand the complex structure of the self, one of which is self-construal. Selfconstrual constitutes ones's feelings, thoughts and actions about oneself, others and the relations with others and has a significant role in behavior both socially and cognitively (Higgins, 1996; Singelis, 1994).

Markus and Kitayama (1991) were the ones that presented the concepts 
of independent and relational self-construals which are widely used today. They emphasized that culture has a determinant role in self-constructs. People who come from cultures where independent self-construal is encouraged have a certain and fixed, individualistic sense of self that places emphasis on focusing on their inner thoughts and feelings, appreciating one's distinctive aspects and revealing oneself. These cultures are generally described as western culture. On the other hand, people from cultures dominated by the relational selfconstruct seem to have a collectivist sense of self where they prioritize focusing on and compliance with others and maintaining a harmonious relationship. These cultures are generally seen in the east (Markus and Kitayama, 1991; Singelis, 1994).

DeCicco and Stroink (2007) stated that the self is not constructed based on only personal qualities, close social relationships or the communities in which people live; and that existing self-constructs do not include a transcendent, universally oriented interpretation. Then they presented a third self-construal named metapersonal self-construct. We see the experiences this selfconstruct is based on, especially in the transpersonal psychology approach.

The transpersonal psychology approach emphasizes the potential of individuals to step beyond the self by going beyond personality and to surrender identification with both external and internal objects (Walsh and Frances, 2001). Walsh and Vaughan (1993, p.3) describe what they call transpersonal experiences as "beyond the individual or personal to encompass wider aspects of humankind, life, psyche, and cosmos".

DeCicco and Stroink (2007), on this ground mentioned above, highlighted the existing deficiency and presented the metapesonal self-construct. It has been seen that there is no scale in the Turkish literature that measures the metapersonal self-construct and that such a scale is needed. In this study, it was aimed to adapt the Metapersonal Self-Construal Scale developed by DeCicco and Stroink (2007) to Turkish and to examine its linguistic-equivalence, validity and reliability.

\section{Method}

There are three different study groups in this research. The first study group consists of 30 undergraduate students, 25 girls, 5 boys, aged between 18 and 25, who study in different departments of a private university in Istanbul. The second study group consists of a total of 376 undergraduate students 
aged between 18 and 25, of which 308 are girls, 65 are boys and 3 are unspecified, and data belonging to this group were collected via Google Forms. The third study group consisted of 108 undergraduate students studying in the education faculty of a private university, between the ages of 18-25, 94 female, 14 male and one unspecified.

In this study, three different measurement tools were used. The first is the Metapersonal Self Construal Scale, which belongs to DeCicco and Stroink (2007). It was adapted to Turkish by the researchers. The second is the Forgiveness Scale. It was developed by Ersanl1 and Vural-Batık in 2015. The last one is the Moral Identity Questionnare, developed by Black and Reynolds (2016) and adapted to Turkish by Sarıçam and Çelik (2018).

The Turkish form was created with the translation and back-translation method. Within the scope of linguistic equivalence analyzes, Turkish and English forms were applied with a 1-week interval and the difference between the forms was examined with the independent samples $t$ Test. Afterwards, confirmatory factor analysis was performed to examine the construct validity of the scale. Since the factor loading of item 10 was below .20, the item was removed from the scale and confirmatory factor analysis was performed. The modification proposed by the program was carried out and the results of the analysis were examined. Criterion related validity results were examined. Within the scope of reliability analysis, Cronbach Alpha coefficient, corrected item-total score correlations and Spearman Brown two half test results were examined.

\section{Results/Discussion}

Confirmatory factor analysis was performed to examine the construct validity. The results were compared with the fit indices and the structure consisting of a single factor with 10 items showed good fit. However, when item factor loadings were analyzed, it was seen that item 10 loaded less than .20. and it was removed from the scale. After the removal, a confirmatory factor analysis was performed and it was observed that some indices did not meet the criteria, so variance errors of items 1 and 9 were combined. When the fit indices were analyzed after the modification, the single factor structure consisting of 9 items showed good fit $\left(\chi^{2}(26, \mathrm{~N}=376)=77.890, p<.001 ; \chi^{2} / \mathrm{sd}=3\right.$; $\mathrm{CFI}=.91 ; \mathrm{SRMR}=.048 ; \mathrm{RMSEA}=.021$, TLI=.88).

The relationships with the Forgiveness Scale and the Moral Identity Questionnare were examined and no significant relationship with Forgiveness 
of Self was found while significant relationships with Forgiveness for Others and Moral Identity were found. While it was an unexpected result that there was no significant relationship with Self Forgiveness, the results obtained with Forgiving Others and Moral Identity were similar to previous studies (Arnocky, Stroink and DeCicco 2007; Chan, Arita, Siu and Angela, 2016; Mara, DeCicco and Stroink, 2010; King and DeCicco, 2009).

The Cronbach Alpha coefficient was found to be .72; the Spearman Brown two half test coefficient calculated between odd and even items was found to be .72 . The adjusted item-total score coefficients were between .28 and .54 .

\section{Conclusion}

Findings from validity, reliability, and linguistic equivalence analyzes show that the Turkish form of the Metapersonal Self-Construal Scale is a valid and reliable measurement tool with linguistic equivalence.

\section{Giriş}

Benlik kavramı, öncelikli olarak felsefenin sonrasında psikolojinin inceleme alanına girmiş, çok boyutlu ve karmaşık bir kavramdır. Bu özelliğinden ötürü Batı felsefe tarihinde en belirsiz kavramlardan biri olarak nitelendirilmiştir (Yalçın, 2010). Psikoloji tarihinde ise ilk olarak William James'in Psikolojinin Prensipleri kitabında önemli bir hacme sahip Benlik Bilinci bölümünde karşımıza çıkmaktadır (Moghaddam, 2013). O tarihten bu yana psikolojide ilgi çeken, temel araştırma alanlarından biri olduğu görülmektedir (Cross, Hardin ve Gercek-Swing, 2009).

William James benliği temel olarak kişinin yaşadığı devamlılık duygusu olarak tanımlar. Bunun yanısıra benlik zihinsel süreçlerin kaynağıdır ve algıları süzen bir filtre işlevine de sahiptir (James, 1981/1890). Benliğin bu karmaşık yapısını anlamak için benlik algısı, benlik saygısı, benlik imgesi, benlik farkındalığı gibi birçok farklı kavramsallaştırmalar ortaya konulmuştur ki (Yıldız, 2006) bunlardan bir diğeri de benlik kurgusu (self-construal) kavramıdır. Construal kelimesi, İngilizce'de yorum, yorumlama bir şeyin anlamını ya da niyetini açıklama (Dalgish, 1996) anlamına gelmektedir. Türkçe alanyazına bakıldığında bu kavramın 'benlik kurgusu' ifadesi ile karşılandığı görülmektedir. Benlik kurgusu, kişinin kendisi, diğerleri ve diğerleri ile ilişkilerine dair duygu, düşünce ve eylemlerinin bütününü oluşturur ve hem sosyal hem bilişsel anlamda davranışlarda belirleyici role sahiptir (Higgins, 1996; 
Singelis, 1994).

Benlik kurgusuna dair araştırmaların temelini Kelly (1955) atmıştır ve kişilerin, deneyimleri doğrultusunda kişisel anlam ve gerçekliklerini kurguladıklarını ifade etmiştir. Baumeister (1998) benliği kurgulamanın özdüşünümsel, kişiler arası ilişkiler ve yönetici işlev adını verdiği üç süreçle oluştuğunu belirterek bu alana katkı yapan bir diğer önemli isimdir. Bugün yaygın şekilde kullanılan bağımsız ve ilişkisel benlik kurgusu kavramlarının ortaya çıkması ise Markus ve Kitayama'nın (1991) farklı kültürlerden gelen kişilerin benlik kurgularının kültürlerine bağlı olarak değiştiğini vurguladıkları çalışmaları ile söz konusu olmuştur.

Markus ve Kitayama (1991) farklı kültürlerden kişilerin benliklerine, diğerlerine ve bu ikisinin ilişkililiğine dair farklı yorumlamalara sahip olduklarını vurgulamıştır. Bağımsız ve ilişkisel şeklinde iki temel benlik kurgusunun olduğunu ve bu kurguların bilişsel, duygusal ve motivasyonel birçok sonucu olduğunu iddia etmişlerdir. Bu noktada en temel fark, kurguların 'diğerlerine' benliği tanımlamada atfettikleri roldür. Bağımsız benlik kurgusunun teşvik edildiği kültürlerden gelen kişiler, kendi içsel düşünce ve duygularına odaklanmayı, kişinin diğerlerinden farklı yanlarını takdir etmesini ve kendini ortaya koymasını önemseyen sınırları belirli ve sabit, bireyselci bir benlik anlayışına sahiptirler. Bu kültürler genel olarak batı kültürü olarak tarif edilmektedir. İlişkisel benlik kurgusunun hâkim olduğu kültürlerden gelen kişilerin ise diğerlerine odaklanmayı ve uymayı ve uyumlu bir ilişkililik halini sürdürmeyi, dışsal özellikleri, rolleri, konumları önceledikleri toplumsalcı bir benlik anlayışına sahip oldukları görülmektedir ki bu kültürler de daha çok doğuya hastır (Markus ve Kitayama, 1991; Singelis, 1994).

Brewer ve Gardner (1996) ile Kashima ve arkadaşları (1995) ise bu çalışmaları bir adım öteye taşıyarak ilişkisel benlik kurgusunun da iki alt kategoride ele almış ve bunlardan birinin ilişkisel diğerinin ise toplulukçu benlik kurgusu olduğunu ifade etmişlerdir. İlişkisel benlik kurgusu daha yakın ilişkileri temel alarak benliğe anlam verilmesini mümkün kılarken toplulukçu benlik kurgusu millet vb ait olunan grupların temel alındığı bir yorumlamayı mümkün kılar. Bu benlik kurgularının her birinin aslında her bir bireyde farklı derecelerde mevcut olduğu fakat kültürel bağlamın özellikle bir tanesini teşvik ettiği (Aaker ve Lee, 2001; Brewer ve Gardner, 1996; Singelis, 1994; Markus ve Kitayama, 1991), ayrıca farklı bağlamlara göre de farklı kurguların aktif olabildiği ve davranışı yönlendirdiği düşünülmektedir (Oyserman ve Lee, 
2008).

DeCicco ve Stroink (2007) benliğin, sadece şahsi nitelikler ya da yakın sosyal ilişkiler, kişilerin içinde bulundukları topluluklar üzerinden kurgulanmadığını ve mevcut benlik kurgularının ben-ötesi, evrensel yönelimli bir anlamlandırmayı kapsamadığını ifade etmişlerdir ve birey-ötesi adını verdikleri üçüncü bir benlik kurgusu modeli ortaya koymuşlardır. Bu benlik kurgusunun temel aldığı deneyimleri özellikle benötesi (transpersonal) psikoloji yaklaşıminda görmekteyiz.

Benötesi psikoloji yaklaşımı bireylerin kişiliğin ötesine geçme ve kimliksel anlamda hem dişsal hem de içsel nesnelerle özdeşleşmekten sıyrılarak benliğin ötesine adım atabilme potansiyelini vurgulamaktadır (Walsh ve Frances, 2001). Walsh ve Vaughan (1993) benötesi deneyimler adını verdikleri deneyimleri "kimlik veya benlik duygusunun, bireysel veya kişisel olanın ötesine geçip, insanlığın, hayatın, psişenin veya kozmosun daha geniş yönlerini kapsayan deneyimler" olarak tanımlamaktadırlar. Ayrıca benötesi yaklaşımın kişisel olanı geçersiz kılıp dışlamadığını, kişiyi hem kişisel hem de benötesi düzeyde ele aldığını vurgularlar.

Doğu kültürünü şekillendiren Taoism, Hinduizm, Budizm ve İslam Sufizmi gibi inanışlar doğrultusunda kişilerin şahit olan benlik, gözlemleyen benlik, kendini kınayan nefis/benlik şeklinde isimlendirilen; James'in de benzer şekilde "bilen benlik" şeklinde isimlendirdiği, kişinin kendisini gözlemlemesini mümkün kılan yanının işletilmesinin hedef gösterildiği görülmektedir ki (Dorman, 2019; Harris, 2017; Ho, 1995; James, 1981/1890) bu sayede kişi özdeşleştiği bireysel özellikler ve deneyimlerden sıyrılıp aşkın ve dolayısıyla evrensel olanla bütünleşme deneyimine yönelmektedir (Ho, 1995; Merter, 2009, s.55). Benzer bir durumu James "Bizim bireysellik dediğimiz şey, evrensel bilincin bütünselliği önüne tesadüfen çıkan bir engeldir. Engin bir deniz gibi olan bu evrensel bilincin içine akıllarımız akarsuların denize ulaşması gibi ulaşır." (akt; Merter, 2009, s.51-52) şeklinde ifade etmektedir. Evrensel ve daha bütünsel bir bilince ulaşma deneyimini Maslow da (1971, akt; Merter, 2009) kendini gerçekleştirme sürecinde yaşanan bir deneyim olarak ele almaktadır ayrıca bu sayede kişinin hakikat ve tabiatla daha yakın ilişki içine girebildiğini de vurgulamaktadır (Holm, 2018).

Benliği birey-ötesi kurgulamanın, ben-ötesi ekoloji yaklaşımında, içinde bulunduğumuz zaman diliminin bir gerekliliği olarak vurgulandığını 
görmekteyiz. Koestler'in (1976) 'holarchy' kavramına dayandırılarak, ekolojik anlamda bütün sistemlerin bir bütünlük içinde olduğu vurgulanmakta ve insanın da bu bilince sahip olmasının içinde yaşadığımız zaman ve evrenin bir gerekliliği olduğu vurgulanmaktadır (Csikszentmihalyi, 1993; Do Rozario, 1997). Benzer şekilde, yaratıcı paradigma adı verilen paradigmaya dayandırılan ekolojik yaklaşıma göre de (Peile, 1994) hayat ve bilinçlilik, bütüncül bir sistem içinde iç içe sarılmıştır. Bir bireyin bilinçliliği, diğer bütün bireylerin bilinçliliğinin içinde sarmalanmıştır ve doğrudan etkileşimle oluşan bağlantının ötesinde bir bağlantı söz konusudur.

DeCicco ve Stroink (2007), yukarıda bahsedilen bu zemin üzerinde, mevcut eksikliğe dikkat de çekerek birey-ötesi benlik kurgusunu ortaya koymuş ve Baumeister'ın (1998) belirlediği benlik kurgularını oluşturan üç sürecin birey-ötesi benlik kurgusunda nasıl geliştiğini açıklamıştır. Özdüşünümsel süreç olan ilk merhalede, kişi, diğer kişiler ve şeyler üzerine derinlemesine düşünmekte, bunları kendi benliğinin bir parçası olarak görmektedir. İkinci merhalede, kişi kendini sosyal bağlamda gözden geçirmekte ve her şey, her grup, her canlı ile bağlantılı olma hali üzerine benliğini anlamlandırmaktadır. Son olarak ise benliğe ait yürütücü işlevin bu anlamlandırma doğrultusunda karar alması ve harekete geçmesi söz konusu olmaktadır.

İnsana bütüncül olarak yaklaşımın insanı anlama ve müdahalede bulunurken önem taşıdığı kabul görmüş bir gerçektir. Bu doğrultuda, benlik kurgusunun, sadece bireysellik ve toplumsallık boyutuyla ele alınıp, birey-ötesi boyutun hesaba katılamaması alan adına ciddi bir eksiklik oluşturmaktadır. Diğer bir ifade ile psikolojide dikkate alınması gerektiği ifade edilen zihinsel, fiziksel ve duygusal boyutlar gibi bir boyut olan ve insanın anlam arayışı ile yakından ilintili olan spiritüel boyutun benliğin kurgulanmasındaki katkısının incelenmesi önem taşımaktadır. Bunun yanı sıra, özellikle günümüzde zamanın ruhunu etkileyen globalleşmenin, diğer zamanlardan çok daha fazla olarak, benliklerimizi evrensellik perspektifinden kurgulamamızda etkili olduğu da göz önünde bulundurulması gereken başka bir durumdur. Bu noktada, Türkçe alanyazın incelendiğinde bu ihtiyacı karşılayacak, birey-ötesi benlik kurgusunu ölçen bir aracın bulunmadığ 1 ve böyle bir araca ihtiyaç olduğu saptanmıştır ve bu çalışmada, DeCicco ve Stroink (2007) tarafından geliştirilen "Birey-Ötesi Benlik Kurgusu Ölçeği”nin Türkçeye uyarlanması, dilsel-eşdeğerliğinin, geçerliliğinin ve güvenilirliğinin incelenmesi amaçlanmıştır. 


\section{Yöntem}

\section{Araştırma Modeli}

$\mathrm{Bu}$ araştırma bir ölçme aracının adaptasyonun yapılması ve psikometrik özelliklerinin değerlendirilmesi amacıyla nicel araştırma yöntemlerinden betimleyici tarama modelinde gerçekleştirilmiştir.

\section{Çalıșma Grubu}

$\mathrm{Bu}$ araştırmada 3 farklı çalışma grubu bulunmaktadır. Çalışma grupları orijinal ölçek çalışmasında olduğu gibi üniversite öğrencilerinden oluşturulmuştur. Veriler 2019 yılında toplanmıştır. Dilsel eşdeğerlik analizlerini gerçekleştirmek için belirlenen ilk çalışma grubu İstanbul'da yer alan bir vakıf üniversitesinin İngilizce Öğretmenliği, \%100 İngilizce Psikoloji ve \%30 İngilizce Rehberlik ve Psikolojik Danışma bölümlerinde okuyan, 25'i (\%83) kız, 5'i (\%17) erkek, yaşları 18-25 arasında değişen 30 lisans öğrencisinden oluşmaktadir.

İkinci çalışma grubu 308'i (\%81.9) kız, 65'i (\%17.3) erkek, 3’ü (\%0.8) cinsiyetini belirtmemiş olan, yaşları 18-25 arasında değişmekte olan toplam 376 ön lisans ve lisans öğrencilerinden oluşmaktadır ve bu gruba ait veri internet üzerinden toplanmıştır. Google Formlar kullanılarak anketler internet ortamına aktarılmış ve 18-25 yaş aralığındaki üniversite öğrencilerinin doldurması gereği ve çalışmanın amacı belirtilerek çeşitli öğrenci grupları (okul/ders grupları, öğrenci kulüpleri, kültürel etkinlik grupları) ile paylaşılmıştır. Belirtilen kriterleri sağlamayan veriler analize dâhil edilmemiştir. İkinci çalışma grubundan elde edilen veriler doğrulayıcı faktör analizini ve güvenirlik analizlerini gerçekleştirmek için toplanmıştır.

Üçüncü çalışma grubu ise ölçek bağıntılı geçerliği incelemek üzere, bir vakıf üniversitesinin eğitim fakültesinde okuyan, 18-25 yaş aralığındaki 108 lisans öğrencisinden toplanmıştır. Öğrencilerin 94'ü (\%86.2) kadın, 14'ü (\%12.8) erkektir; bir kişi cinsiyetini belirtmemiştir.

\section{Veri Toplama Araçları}

\section{Birey-Ötesi Benlik Ölçeği}

DeCicco ve Stroink (2007) tarafından, bağımsız ve ilişkisel/toplulukçu benlik kurgularına ek olarak, üçüncü bir benlik kurgusu olan birey-ötesi benlik kurgusunu ölçmek üzere 7'li likert tipinde geliştirilmiştir. On madde ve tek boyuttan oluşmaktadır. Ölçekte ters madde bulunmamakta ve maddelerin toplam puanı üzerinden ölçek puanı elde edilmektedir. Alınan yüksek puan birey- 
ötesi benlik kurgusu düzeyinin yüksekliğine işaret etmektedir. Cronbach Alfa değeri .80'dir. Bağımsız ve ilişkisel benlik kurgusuna ait ölçek sorularının da dâhil edildiği bir çalışmada yapılan açımlayıcı ve doğrulayıcı faktör analizi ile birey-ötesi benlik kurgusunun diğer benlik kurgularından farklı bir yapıyı ölçtüğü doğrulanmıştır. Birey-ötesi benlik kurgusu maddelerinden birinin ilişkisel, birinin bağımsız benlik kurgusunda yüklendiği; diğer maddenin ise herhangi bir kurguda yer almadığı görülmüştür fakat güvenirlik analizleri sonucunda maddenin korunması yönünde karar verilmiştir. Ölçüt bağıntılı geçerlik kapsamında, canlılık ve affedicilik ile pozitif; anksiyete, belirsizliği tolere etme, modern 1rkçılık ile negatif yönlü anlamlı ilişkiler bulunmuştur.

Birey-ötesi benlik kurgusu, diğer tüm varlıklarla birlik içindelik, bağlantıl111k halinin kişide kararlaşması, benliğini kurgularken ve eylemlerini belirlerken bunu temel alması olarak özetlenebilir (Arnocky, Stroink ve DeCicco 2007; Brown, DeCicco ve Stroink, 2005). Kişinin benliğini bu temeller üzerine kurgulamasının, ben-öteki arasındaki sınırları kaldırarak affetmeyi kolaylaştırması beklenmektedir. Ayrıca, eylemlerinin ve kimliğinin temelini benmerkezlilik ya da toplum-merkezlilik yerine evrenselliğin ve kâinattaki tüm varlıklarla bir olma halinin almasının da ahlaki kimliği besleyeceği düşünülmektedir ki Maslow'un (1970) ihtiyaçlar hiyerarşisinde açıkladığ kendini gerçekleştiren insanların vasıfları da bu görüşü desteklemektedir. Ölçeğin geliştirilmesi sürecinde raporlanan affedicilik ile pozitif ve modern 1rkçılıkla negatif yönlü ilişkileri de bu varsayımları desteklemektedir (DeCicco ve Stroink, 2007). Bu sebeple bu çalışmada ölçüt bağıntılı geçerlik kapsamında "Affetme Ölçeği” (Ersanlı ve Vural-Batık, 2015) ve "Ahlaki Kimlik Ölçeği””nden (Sar1çam ve Çelik, 2018) yararlanılmıştır.

\section{Affetme Ölçeği}

Ersanlı ve Vural-Batık tarafindan 2015 yılında geliştirilmiştir. Kendini affetme ve başkasını affetme şeklinde 2 boyuttan ve toplam 13 maddeden oluşmaktadır. Alınan puanlardaki artış, affetme düzeyinde artışı ifade etmektedir. 7'li likert tipi bir derecelendirmeye sahiptir. 1, 2, 3, 6, 7 ve 8. maddeler ters puanlanmaktadır. Yapılan açımlayıcı faktör analizi sonucunda 2 faktörlü yapının iyi uyum gösterdiği ifade edilmiştir. Cronbach Alfa iç tutarlılık güvenirlilik katsayıları kendini affetme için .82, başkasını affetme için .76 ve ölçeğin bütünü için .74 olarak bulunmuştur. Ölçüt bağıntılı geçerlik kapsamında, tolerans ölçeği ile ilgili korelasyon değerleri hesaplanmış ve pozitif yönlü ilişki bulunmuştur. 


\section{Ahlaki Kimlik Ölçeği}

Black ve Reynolds (2016) tarafından geliştirilip Sarıçam ve Çelik (2018) tarafından Türkçe'ye uyarlanmıştır. Ahlaki benlik, ahlaki sağlamlık şeklinde 2 alt boyuttan oluşmakta ve ayrıca ölçekten toplam puan elde edilebilmektedir. 6'l1 likert tipi bir derecelendirmeye sahiptir. Ölçeğin 9-20. Maddeleri ters kodlanmaktadır. Artan puanlar ahlaki kimlik düzeyinde artış ifade etmektedir. Cronbach Alfa iç tutarlılık güvenirlilik katsayıları ölçeğin bütünü için .90 ve alt faktörlerden ahlaki benlik için .77, ahlaki sağlamlık için .92 olarak bulunmuştur. Ölçüt bağıntılı geçerlik kapsamında "Makyavelizm Ölçeği” ve "Maneviyat Ölçeği” ile arasında istatistiksel olarak anlamlı ilişkiler bulunduğu bildirilmiştir. Ölçeğin düzeltilmiş madde toplam korelasyon değerleri .30 ile .74 arasında değişmektedir.

\section{Veri Toplanması ve Analizi}

Öncelikle ilgili araştırmacı ile e-posta yoluyla iletişime geçilerek ölçeği Türkçe'ye uyarlamak üzere izin alınmıştır. Sonrasında biri iki-dilli olmak üzere lisansüstü seviyesinde eğitime sahip çok iyi derecede İngilizce bilen 5 kişi tarafindan ölçeğin İngilizce'den Türkçe'ye çevirileri gerçekleştirilmiştir. Taslak metinler 2 Rehberlik ve Psikolojik Danışma uzmanı tarafından incelenerek Türkçe formun son hali oluşturulmuştur ve bu form iyi derecede İngilizce bilen başka bir kişi tarafından İngilizce'ye geri çevrilmiştir. Son çeviri ve ölçeğin orijinal metni incelenmiş, gerekli düzenlemeler yapılmış ve ölçeğin Türkçe formu oluşturulmuştur.

Toplanan verilerin analizi sürecince öncelikle SPSS 25.0 programı kullanılarak standartlaştırılmış z değerleri incelenerek uç değerler veriden çıkartılmıştır. Kayıp veri analizi yapılmış ve $\% 5$ 'ten fazla kayıp veri olan madde olmadığ 1 görülmüsstür. EM yöntemi ile veri ataması yapılmıştır. Normallik dağlımları, çarpıklık, basıklık değerleri incelenmiş ve normallik varsayımının sağlandığı görülmüştür. İkinci çalışma grubunda çok boyutlu normallik varsayımını sağlamadığı görülen 3 kişi veriden çıkartılırken, üçüncü çalışma grubunda uç veri olduğu tespit edilen 12 kişi veriden çıkartılmıştır. Dilsel eşdeğerlik analizleri kapsamında 1 hafta ara ile uygulanan Türkçe ve İngilizce formlar arasındaki fark, ilişkili örneklem $t$ Testi ile incelenmiştir. Sonrasında ölçeğin yapı geçerliğini incelemek üzere Mplus programı ile doğrulayıcı faktör analizi yapılmıştır. Madde 10'un faktör yükünün .20'nin altında olması 
sebebiyle madde ölçekten çıkartılarak tekrar doğrulayıcı faktör analizi uygulanmıştır. Programın önerdiği modifikasyon gerçekleştirilerek analiz sonuçları incelenmiştir. Ölçüt bağıntılı geçerlik sonuçları incelenmiştir. Güvenirlik analizleri kapsamında ise Cronbach Alfa katsayısı, düzeltilmiş madde-toplam puan korelasyonları ve Spearman Brown iki yarım test sonuçları incelenmiştir.

\section{Bulgular}

\section{Dilsel Eşdeğerlik}

Dilsel eşdeğerliği değerlendirmek üzere çalışma grubuna bir hafta ara ile önce İngilizce sonra Türkçe form uygulanmış hem madde hem de toplam puan bazında, korelasyon değerleri ve ilişkili örneklem $t$ Testi sonuçları incelenmiş Tablo 1 ve 2'de sunulmuştur.

Tablo 1. Dilsel Eşdeğerlik için İlişkili Örneklem $t$ Testi Sonuçları

\begin{tabular}{llcccc}
\hline Madde & Form & $\overline{\mathbf{x}}$ & $\mathbf{s s}$ & $\mathbf{t}$ & $\boldsymbol{p}$ \\
\hline Madde 1 & İngilizce & 5.30 & 1.39 & -1.68 & .103 \\
& Türkçe & 5.57 & 1.36 & & \\
Madde 2 & İngilizce & 4.37 & 1.92 & -.96 & .345 \\
& Türkçe & 4.60 & 1.67 & & \\
Madde 3 & İngilizce & 4.87 & 1.42 & -.93 & .362 \\
& Türkçe & 5.03 & 1.33 & & \\
Madde 4 & İngilizce & 5.90 & 1.42 & .24 & .813 \\
& Türkçe & 5.87 & 1.33 & & \\
Madde 6 & İngilizce & 4.57 & 1.50 & -1.63 & .114 \\
& Türkçe & 5.00 & 1.39 & & \\
Madde 7 & İngilizce & 5.13 & 1.66 & -.61 & .546 \\
& Türkçe & 5.27 & 1.48 & & \\
Madde 8 & İngilizce & 4.97 & 1.47 & .60 & .555 \\
& Türkçe & 4.83 & 1.49 & & \\
Madde 9 & İngilizce & 5.20 & 1.73 & -.37 & .712 \\
& Türkçe & 5.30 & 1.49 & & \\
Madde 10 & İngilizce & 4.20 & 1.42 & -1.55 & .333 \\
& Türkçe & 4.57 & 1.52 & & \\
\hline
\end{tabular}

Dilsel eşdeğerliği değerlendirmek üzere yapılan ilişkili örneklem $t$ Testi sonucunda maddelerin İngilizce ve Türkçe formları arasında anlamlı bir farklılık olmadığ 1 görülmüştür ( $p>.05)$. 
Tablo 2. Dilsel Eşdeğerlik için Pearson Momentler Çarpımı Korelasyon Katsay1lar1

\begin{tabular}{llll}
\hline Madde & $\mathbf{N}$ & $\mathbf{r}$ & $\boldsymbol{p}$ \\
\hline Madde 1 & 30 & .80 & .000 \\
Madde 2 & 30 & .73 & .000 \\
Madde 3 & 30 & .76 & .000 \\
Madde 4 & 30 & .85 & .000 \\
Madde 5 & 30 & .66 & .000 \\
Madde 6 & 30 & .50 & .005 \\
Madde 7 & 30 & .72 & .000 \\
Madde 8 & 30 & .66 & .000 \\
Madde 9 & 30 & .59 & .001 \\
\hline Madde 10 & 30 & .61 & .000 \\
\hline
\end{tabular}

Ölçeğin maddelerinin İngilizce ve Türkçe formları arasındaki ilişki Pearson Momentler Çarpımı Korelasyonu katsayılarına bakılarak incelenmiş ve her bir maddenin anlamlı şekilde ilişkili olduğu görülmüştür $(p<.01)$. İlişkili örneklem $t$ Testi sonuçları ile değerlendirildiğinde "Birey-Ötesi Benlik Ölçeği”nin Türkçe formunun İngilizce form ile dilsel eşdeğerliğe sahip olduğu görülmektedir.

\section{Yapı Geçerliği}

Ölçeğin yapı geçerliğini incelemek üzere yapılan doğrulayıcı faktör analizi sonucunda uyum indeksleri incelendiğinde ölçeğin orjinalinde olduğu gibi 10 maddeden oluşan tek faktörlü yapının iyi sonuç verdiği görülmüştür (Model 1, $\chi^{2}(35, \mathrm{~N}=376)=62.20, p<.001 ; \chi^{2} / \mathrm{sd}=1.77 ; \mathrm{CFI}=.90 ; \mathrm{SRMR}=.05$; RMSEA $=.06, T L I=.87$ ). Ölçeğin faktör yükleri incelendiğinde, madde 10 'un .20'den düşük yüklendiği görülmüştür. Dilsel eşdeğerlik analizlerinde dilsel anlamda madde 10'un Türkçe versiyonunun İngilizce versiyona eşdeğer olduğu görülmesine rağmen bu maddenin Türk örnekleminde ilgili alanı ölçmede yetersiz olduğu gözlemlendiğinden ölçekten çıkarılması uygun görülmüştür. Bunun üzerine 9 maddelik tek faktörlü yapı için tekrar doğrulayıcı faktör analizi uygulanmıştır ve bazı uyum indekslerinde yeterli düzeyin karş1lanmadığ1 görüldüğünden (Model $2, \chi^{2}(27, \mathrm{~N}=376)=97.21, p<.001 ; \chi^{2} / \mathrm{sd}=3.6$; $\mathrm{CFI}=.88$; $\mathrm{SRMR}=.05 ; \mathrm{RMSEA}=.00, \mathrm{TLI}=.84) 1$. ve 9. maddeler arasinda modifikasyon gerçekleştirilmiştir. Modifikasyon sonrası uyum indeksleri incelendiğinde 9 maddeden oluşan tek faktörlü yapının iyi sonuç verdiği görülmüştür (Model 3, $\chi^{2}(26, \quad \mathrm{~N}=376)=77.89, \quad p<.001 ; \chi^{2} / \mathrm{sd}=3 ; \quad \mathrm{CFI}=.91$; $\mathrm{SRMR}=.05$; RMSEA=.02, TLI=.88). Uyum indekslerini gösteren değerler Tablo 3 'te sunulmuştur. 
Tablo 3. Birey-Ötesi Benlik Ölçeğinin Uyum İndeksleri Değerleri

\begin{tabular}{llllcr}
\hline & $\chi \mathbf{2} / \mathbf{s d}$ & CFI & RMSEA & SRMR & TLI \\
\hline Model 1 & 1.77 & .90 & .06 & .05 & .87 \\
Model 2 & 3.60 & .88 & .00 & .05 & .84 \\
\hline Model 3 & 3.00 & .91 & .02 & .05 & .88 \\
\hline
\end{tabular}

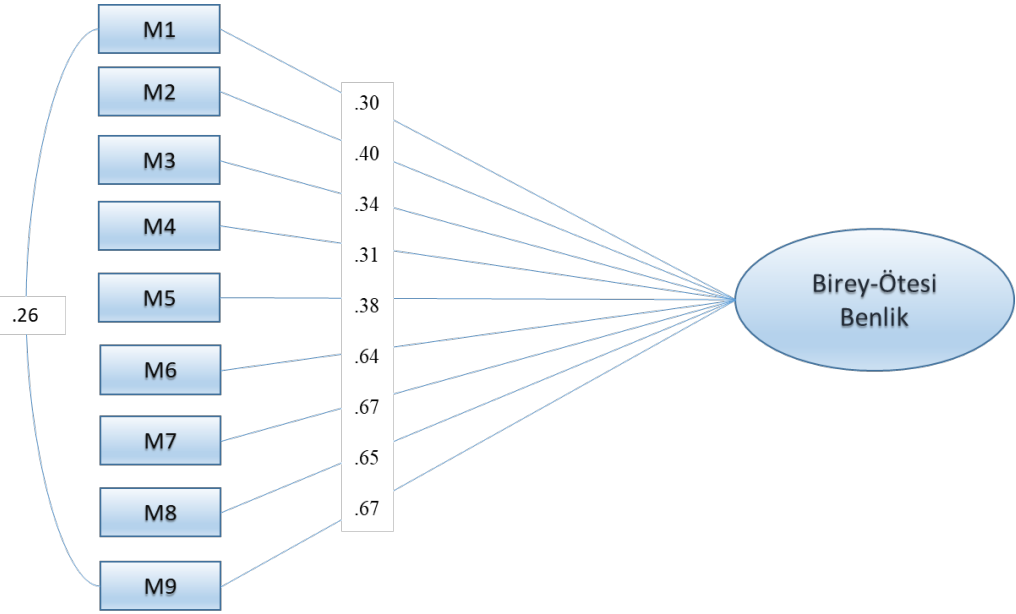

Şekil 1. Birey-Ötesi Benlik Ölçeği Faktör Yüklerini Gösterir Yol Diyagramı

Doğrulayıcı faktör analizi sonucu ortaya çıkan faktör yapısı ise Şekil 1 'de sunulmuştur. Ölçeğin faktör yüklerinin .30 ile .67 arasında değiştiği görülmektedir.

\section{Ölçüt Bağıntılı Geçerlik}

Ölçüt-bağıntılı geçerlik analizleri kapsamında, affetme ölçeği ve ahlaki kimlik ölçeği ile arasındaki ilişkilere bakılmıştır. İlgili ilişkilere ait korelasyon katsayılarını gösteren bulgular Tablo 4'te sunulmuştur. Buna göre "BireyÖtesi Benlik Ölçeği” ile “Affedicilik Ölçeği”nin alt boyutlarından Kendini Affetme ile istatistiksel olarak anlamlı bir ilişki bulunamazken ( $p>.05)$, Başkasını Affetme ile pozitif yönlü anlamlı bir ilişkisi olduğu görülmüştür (r= $.325, p<.05)$ Ayrıca "Birey-Ötesi Benlik Ölçeği” ile "Ahlaki Kimlik Ölçeği" toplam puanı ile de pozitif yönlü anlamlı ilişki bulunmuştur $(\mathrm{r}=.24, p<.05)$.

Tablo 4. Birey-Ötesi Benlik Kurgusu ile Affedicilik ve Ahlaki Kimlik Düzeyleri Arasındaki İlişkilere Yönelik Korelasyon Katsayıları

\begin{tabular}{llll}
\hline Ölçek & Kendini Affetme & Başkasını Affetme & Ahlaki Kimlik \\
\hline Birey-Ötesi Benlik & .11 & $.32^{* *}$ & $.24^{*}$ \\
\hline${ }^{*} p<.05,{ }^{* *} p<.01$ & & &
\end{tabular}




\section{Güvenirlik}

Güvenirlik analizleri kapsamında düzeltilmiş madde-toplam puan korelasyonları, Cronbach Alfa katsayısı ve iki yarım-test sonuçları incelenmiştir. Düzeltilmiş madde-toplam puan korelasyonlarına ait sonuçlar Tablo 5 'te sunulmuştur.

Tablo 5. "Birey-Ötesi Benlik Ölçeği” Maddelerinin Düzeltilmiş Madde-Toplam Puan Korelasyon Değerleri

\begin{tabular}{ll}
\hline Maddeler & $\begin{array}{l}\text { Düzeltilmiş } \\
\text { Madde-Toplam Puan } \\
\text { Korelasyonları }\end{array}$ \\
\hline $\begin{array}{l}\text { 1. Varlığım, çok anlamlı ve amaçlı. } \\
\text { 2. Nerede olursam olayım, ne yaparsam yapayım diğerlerinden }\end{array}$ & .40 \\
hiçbir zaman ayrı olmadığıma inanıyorum. & .28 \\
3. Tüm canlılara karşı gerçek bir yakınlık hissediyorum. & .33 \\
$\begin{array}{l}\text { 4. İ̧ huzurum benim için en önemli şeylerden biridir. } \\
\text { 5. Her gün sessizliği ve huzuru deneyimlemek ve zihnimdeki }\end{array}$ & .34 \\
günlük düşünceleri boşaltmak için zaman ayırırım. & .27 \\
$\begin{array}{l}\text { 6. Sezginin, benliğimin daha yüce bir kısmından geldiğine ina- } \\
\text { nırım ve onu asla görmezden gelmem. }\end{array}$ & .30 \\
$\begin{array}{l}\text { 7. Kâinata karşı aidiyet ve sorumluluk hissediyorum. } \\
\text { 8. Kimlik duygum beni tüm insanlarla birleştiren bir şey üze- } \\
\text { rine kuruludur. }\end{array}$ & .54 \\
9. Tüm canlılarla aramda bir bağ olduğunun farkındayım. & .51 \\
\hline
\end{tabular}

Ölçek toplam puanına ait Cronbach Alfa katsayısı .72 olarak tespit edilmiştir. Madde-toplam puan korelasyonlarının .27 ile .54 arasında değiştiği görülmektedir. Sadece Madde 2 ve Madde 5'in .30'un altında bir değere sahip olduğu görülmektedir. Ölçekten çıkarılması durumunda Cronbach Alfa katsayısında artış olmadığı gözlemlendiği ve madde sayısının az olduğu durumlarda .20-.30 arasındaki maddelerin korunabileceği (Büyüköztürk, 2018) göz önünde bulundurularak madde 2 ve 5 'in ölçekten çıkarılmaması uygun görülmüştür.

Güvenirlik analizleri kapsamında tek ve çift sayılı maddeler şeklinde test iki yarıya ayrılarak Spearman Brown iki yarım katsayısı hesaplanmış ve .72 olarak tespit edilmiştir.

\section{Sonuç ve Tartışma}

Bu çalışmada DeCicco ve Stroink (2007) tarafindan geliştirilen "BireyÖtesi Benlik Ölçeği”nin Türkçe’ye uyarlanması ve psikometrik özelliklerinin incelenmesi amaçlanmıştır. Dilsel eşdeğerlik, geçerlik ve güvenirlik ile ilgili bulgular aşağıda tartışılmıştır. 
Öncelikle çeviri-geri-çeviri yöntemiyle oluşturulan Türkçe formun dilsel eşdeğerliğe sahip olduğu tespit edilmiştir. Yapı geçerliğini incelemek üzere gerçekleştirilen doğrulayıcı faktör analizi sonucunda 10 madde tek faktörden oluşan yapının orijinal çalışmada olduğu gibi iyi uyum gösterdiği görülmüştür. Fakat madde faktör yükleri incelendiğinde, madde 10'un .20'den düşük yüklendiği görülmüştür. Dilsel eşdeğerlik analizlerinde dilsel anlamda madde 10'un Türkçe versiyonunun İngilizce versiyona eşdeğer olduğu görülmesine rağmen bu maddenin Türk örnekleminde ilgili alanı ölçmede yetersiz olduğu gözlemlendiği için ölçekten çıkarılması uygun görülmüştür. McCrae and Costa'nın da (1999) ifade ettiği üzere, kültür bireysel yatkınlıkların bağlamı ve türünde belirleyici olabilmektedir. Bu anlamda dilsel eşdeğerliğin sağlanmasına rağmen kültürel farklılıklardan dolayı ölçek maddeleri farklı kültürlerde farklı şekilde işleyebilmektedir. Madde 10 "Kendimi, her varlıkta bir uzantım var gibi görüyorum.” cümlesinden oluşmaktadır. Araştırma kapsamında katılımcıların inançlarına dair veri toplanmamış olmakla birlikte, ana akım Türk-Müslüman kültürünün baskın olduğu göz önünde bulundurulduğunda, kişinin her varlıkta bir uzantısının olması hissiyatının, animizm ya da panteizm inançlarını çağrıştırmış olabileceği ve bu sebeple katılımcıların bu maddeyi kendi inançlarına uzak görmüş olabilecekleri düşünülmüştür. Madde 10 'un çıkartılmasından ve yapılan modifikasyondan sonra uyum indeksleri incelendiğinde 9 maddeden oluşan tek faktörlü yapının iyi sonuç verdiği görülmüştür.

Ölçüt bağıntılı geçerlik kapsamında "Affetme Ölçeği” ve "Ahlaki Kimlik Ölçeği" ile ilişkiler incelenmiş ve kendini affetme ile anlamlı bir ilişki olmadığı görülürken, başkalarını affetme ve ahlaki kimlik ile anlamlı ilişkiler tespit edilmiştir. Birey-ötesi benlik ile ilgili yapılan çalışmalarda modern 1rkçlık ile negatif (DeCicco ve Stroink, 2007), duygusal zeka ile pozitif (Mara, DeCicco ve Stroink, 2010); spiritüel zeka ile pozitif (Chan, Arita, Siu ve Angela, 2016; King ve DeCicco, 2009); çevreye dair ilgi ve tutumlar dahilinde biyosferle ilgili olma, kaynakları paylaşma konusunda ekolojik iş birliği tutumuna sahip olma ve çevre yanlısı davranışlara sahip olma (Arnocky, Stroink ve DeCicco 2007) ile pozitif ilişkiler bildirilmiştir. Bu bulguların başkalarını affetme ve "toplum içindeki diğer kişilere zarar vermekten kaçınmanın temel bir kaidesi" (Graham, Nosek, Haidt, Iyer, Koleva ve Ditto, 2011) olarak nitelendirilen ahlaki kimlik ile örtüştüğü görülmektedir. Kendini affetme ile ise beklenen ilişki bulunamamıştır. İlişki katsayılarının .20 ile .40 arasında ol- 
ması, düşük ve kabul edilebilir düzeyde ilişkiye işaret etmektedir ki ölçüt bağıntılı geçerliliğinin kısmen sağlandığı söylenebilir. İleriki çalışmalarda aracı değişkenlerin kullanılmasının ilişkisel yapıları ortaya çıkarmada daha etkili olacağı düşünülmektedir.

Güvenirlik analizleri kapsamında Cronbach Alfa katsayısı .72 olarak; tek ve çift sayılı maddeler arasında hesaplanan Spearman Brown iki yarı test katsayısı ise .72 olarak tespit edilmiştir. Ölçeğin geliştirildiği çalışmada da 10 maddelik form için Cronbach Alfa katsayısı .80 olarak tespit edilmiştir. Madde analizi kapsamında düzeltilmiş madde-toplam puan katsayılarının .28 ile .54 arasında oldukları görülmüştür. .30'un altında kalan iki madde (madde 2 ve 5), silinmesi durumunda Cronbach Alfa katsayısında artışa yol açmaması ve ölçek madde sayısının az olduğu durumlarda. 30'un altında kalan maddelerin korunabileceği görüşüne (Büyüköztürk, 2018) dayanarak korunmuştur.

Araştırmanın bazı sınırlılıkları bulunmaktadır. Bunlar çalışma gruplarının sadece üniversite öğrencilerinden oluşması ve erkek öğrenci sayısının kız öğrencilere kıyasla az olması şeklinde özetlenebilir. Benliği anlamlandırmanın hayatla birlikte gelişen ve değişen dinamik yapısı düşünüldüğünde, yapılacak sonraki çalışmaların farklı yaş grupları ve çeşitli kültürlerden kişilerle yürütülmesi ve cinsiyet dağılımının dengeli olmasının göz önünde bulundurulması faydalı olacaktır. Ayrıca bu çalışmada güvenirlik analizleri kapsamında, iç tutarlılık katsayıları ve Spearman Brown iki yarım katsayısı incelenmiştir. Gelecek çalışmalarda test-tekrar test güvenirlik analizlerinin yapılması faydalı olacaktır.

Geçerlik, güvenirlik ve dilsel eşdeğerlik çalışmalarından elde edilen bulgular, yeni bir benlik kurgusunu ortaya koyan ve ölçen "Birey-Ötesi Benlik Ölçeğì”nin Türkçe formunun dilsel eşdeğerliğe sahip, geçerli ve güvenilir bir ölçme aracı olduğunu göstermektedir.

\section{Kaynakça}

Aaker, J. L. ve Lee, A. Y. (2001). "I" seek pleasures and "we" avoid pains: The role of self-regulatory goals in information processing and persuasion. Journal of Consumer Research, 28, 33-49.

Doi: $10.1086 / 321946$

Arnocky, S., Stroink, M. ve DeCicco, T. (2007). Self-construal predicts environmental concern, cooperation, and conservation. Journal of Environmental Psychology, 27(4), 255-264.

Baumeister, R. F. (1998). The self. D.T. Gilbert, S.T. Fiske ve G. Lindzey, (Ed.), The 
handbook of social psychology (4. bask1) içinde (680-740). New York: McGraw-Hill.

Black, J. E. ve Reynolds, W. M. (2016). Development, reliability, and validity of the Moral Identity Questionnaire. Personality and Individual Differences, 97, 120-129.

Brewer, M. B. ve Gardner, W. (1996). Who is this "we"? Levels of collective identity and self representations. Journal of Personality and Social Psychology, 71, 8393.

Doi: $10.1037 / 0022-3514.71 .1 .83$

Brown, P., DeCicco, T. L. ve Stroink, M. L. (2005). The investigation of the relationship among personality, self-construal, distress, and adaptiveness in university students. Canadian Psychological Association Annual Convention'da sunulan bildiri, Montreal, QC, Canada.

Büyüköztürk, Ş. (2018). Sosyal bilimler için veri analizi el kitabı. İstanbul: Pegem Akademi.

Chan, Y., Arita, W., Siu, Y. ve Angela, F. (2016). Application of the spiritual intelligence self-report inventory (SISRI-24) among Hong Kong University students. International Journal of Transpersonal Studies, 35(1), 1-12.

Cross, S. E., Hardin, E. E. ve Gercek-Swing, B. (2011). The what, how, why, and where of self-construal. Personality and Social Psychology Review, 15(2), 142-179.

Csikszentmihalyi, M. (1993). The evolving self: A psychology for the third millennium. New York: Harper Perennial.

DeCicco, T. L. ve Stroink, M. L. (2007). A third model of self-construal: The metapersonal self. International Journal of Transpersonal Studies, 26(1), 82-104.

Dalgish, G. M. (1996). Random house dictionary. New York: Random House.

do Rozario, L. (1997). Shifting paradigms: The transpersonal dimensions of ecology and occupation. Journal of Occupational Science, 4(3), 112-118.

Dorman, E. (2017). Kendini kınayan nefis. İstanbul: Destek Yayınları.

Ersanl, K. ve Batık, M. V. (2015). Development of the forgiveness scale: A study of reliability and validity. Turkish Studies, 10(7), 19-32.

Graham, J., Nosek, B. A., Haidt, J., Iyer, R., Koleva, S. ve Ditto, P. H. (2011). Mapping the moral domain. Journal of personality and social psychology, 101(2), 366-385.

Doi: $10.1037 / \mathrm{a} 0021847$

Harris, R. (2017). ACT'i kolay ögrenmek: Illkeler ve ötesi için bir başlangıç. İstanbul: Litera Yayıncılik.

Higgins, E. T. (1996). The "self digest": self-knowledge serving self-regulatory functions. Journal of Personality and Social Psychology, 71(6), 1062-1083.

Ho, D. Y. (1995). Selfhood and identity in Confucianism, Taoism, Buddhism, and Hinduism: contrasts with the West. Journal for the Theory of Social Behaviour, 25(2), 115-139.

Holm, N. G. (2018). Din psikolojisine giriş. İstanbul: İnsan Yayınları.

James, W. (1981). The principles of psychology. Cambridge, MA: Harvard University Press.

James, W. (1999) The varieties of religious experience. New York: The Modern Library. 
Kashima, Y., Yamaguchi, S., Kim, U., Choi, S., Gelfand, M. J. ve Yuki, M. (1995). Culture, gender, and self: A perspective from individualism-collectivism research. Journal of Personality and Social Psychology, 69, 925-937. Doi:10.1037/0022-3514.69.5.925

Kelly, G. A. (1955). The psychology of personal constructs (1-2. cilt). New York: Norton.

King, D. B. ve DeCicco, T. L. (2009). A viable model and self-report measure of spiritual intelligence. International Journal of Transpersonal Studies, 28, 6885.

Koestler, A. (1976). The ghost in the machine. New York: Random House.

Mara, C. A., DeCicco, T. L. ve Stroink, M. L. (2010). An investigation of the relationships among self-construal, emotional intelligence, and well-being. The International Journal of Transpersonal Studies, 29(1), 1-11.

Markus, H. R. ve Kitayama, S. (1991). Culture and the self: Implications for cognition, emotion, and motivation. Psychological Review, 98, 224-253.

Doi:10.1037/0033-295X.98.2.224

Maslow, A. H. (1970). Motivation and personality. New York: Harper \& Row.

McCrae, R. R. ve Costa Jr, P. T. (1999). A five-factor theory of personality. In O. P. John, R. W. Robins ve L. A. Pervin (Eds.), Handbook of personality: Theory and research (139-153). New York: Guilford

Merter, M. (2009). Dokuz yüz katll insan: Tasavvuf ve benötesi psikolojisi (Transpersonal psikoloji). İstanbul: Kaknüs Yayınları.

Moghaddam, F. M. (2013). Great ideas in psychology: A cultural and historical introduction. Oxford: Oneworld Publications.

Oyserman, D. ve Lee, S. W. S. (2008). Does culture influence what and how we think? Effects of priming individualism and collectivism. Psychological Bulletin, 134, 311-342.

Doi:10.1037/0033-2909.134.2.311

Peile, C. (1994). The creative paradigm: Insight, synthesis and knowledge development. Sydney: Avebury.

Sarıçam, H. ve Çelik, İ. (2018). Ahlaki kimlik ölçeğinin Türkçe uyarlamasının beliren yetişkinlerde psikometrik özellikleri. 27. Uluslararası Eğitim Bilimleri Kongresi'nde sunulan bildiri, Antalya.

Singelis, T. M. (1994). The measurement of independent and inter-dependent selfconstruals. Personality and Social Psychology Bulletin, 20, 580-591.

Doi:10.1177/0146167294205014

Walsh, R. N. ve Vaughan, F. E. (1993). Paths beyond ego: The transpersonal vision. New York: TarcherPerigee Books.

Walsh, R. N. ve Vaughan, F. (2001). Kişi nedir? Walsh, R. N. ve Vaughan, F. (Ed.), Ego ötesi (H. Ekşi, Çev.) içinde (67-79). İstanbul: İnsan Yayınları.

Yalçın, Ş. (2010). Modern felsefede benlik. İstanbul: Boğaziçi Üniversitesi Yayınevi. Yıldız, M. (2006). Benlik kavramı ve benliğin gelişiminde dinin rolü. Dokuz Eylül Üniversitesi İlahiyat Fakültesi Dergisi, 23, 87-127. 